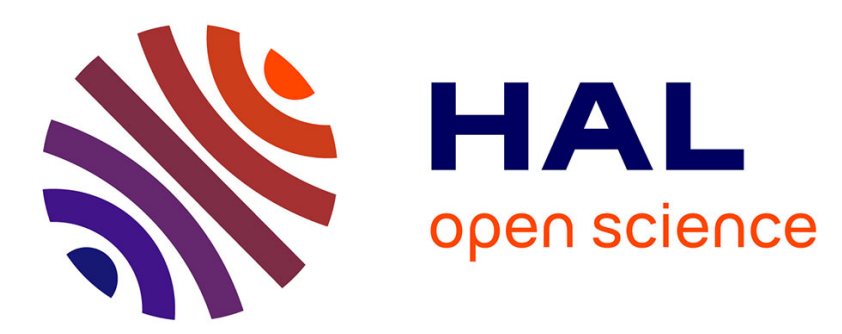

\title{
Bridging Virtual and Real Worlds: Enhancing Outlying Clustered Value Creations
}

Daniel D. Bretonès, Bernard Quinio, Gilbert Réveillon

\section{To cite this version:}

Daniel D. Bretonès, Bernard Quinio, Gilbert Réveillon. Bridging Virtual and Real Worlds: Enhancing Outlying Clustered Value Creations. Journal of Strategic Marketing, 2010, 18 (7), pp.613-625. 10.1080/0965254X.2010.529157 . hal-01755738

\section{HAL Id: hal-01755738 \\ https://hal.parisnanterre.fr/hal-01755738}

Submitted on 30 Oct 2018

HAL is a multi-disciplinary open access archive for the deposit and dissemination of scientific research documents, whether they are published or not. The documents may come from teaching and research institutions in France or abroad, or from public or private research centers.
L'archive ouverte pluridisciplinaire HAL, est destinée au dépôt et à la diffusion de documents scientifiques de niveau recherche, publiés ou non, émanant des établissements d'enseignement et de recherche français ou étrangers, des laboratoires publics ou privés. 


\title{
Bridging virtual and real worlds: enhancing outlying clustered value creations
}

\author{
Daniel D. Bretonès ${ }^{\mathrm{a} *}$, Bernard Quinio ${ }^{\mathrm{b}, \mathrm{c}}$ and Gilbert Réveillon ${ }^{\mathrm{b}}$ \\ ${ }^{a}$ Département Management, Stratégie, et Systèmes, Université Centre Val de Loire/ESCEM, 11, rue \\ de l'Ancienne Comédie, Poitiers, 86001, France; ${ }^{b}$ Département Gestion, Université Paris Ouest, \\ 200, avenue de la République, Nanterre, 92001, France; ${ }^{c}$ Département Information, Opérations \\ Management, ESCP EUROPE, 79 avenue de la République, Paris, France
}

\begin{abstract}
Virtual worlds and virtual social networks provide real opportunities for companies to implement research in management dealing with immersive environment, interaction and co-creation of values (artefact, process, knowledge). New capabilities and new tools are emerging. The observations drawn from experiments allow categorizing them. We then propose an approach that could help companies to start activities inside these new environments of collaborative work. The cross fertilizing insights between the virtual and the real world are shown and introduced as the bridge. The 3D economy process is based on shorter cycles of decision making processes. The 'bridge model' integrates the added value chain and goes beyond it with the creation of outlying clustered values. The bridge mechanism shows a spectrum from low potential to high potential areas - of fulfillments. A company strategy may explain a positioning on one or the other limits of the spectrum.
\end{abstract}

Keywords: bridge; clustered value creations; innovation; social networks; virtual worlds

\section{Introduction}

The three dimensional economy (3D) illustrated through virtual worlds (VW) and virtual social networks (VSN) provide real opportunities for companies in the fields of immersion, interaction and value co-creation. VW without at least one individual member of a VSN, being linked synchronously or asynchronously due to persistence characteristics of the online world, is an empty space out of our scope. For practical reasons, when 'VW' is mentioned in this document it means 'VW and 3D VSN' including serious games and Massively Multiplayer Online Role Playing Games (MMORPG). Inputs coming from R\&D and management practices suggest that between the digital environment and the reality there is a mutual enrichment process. 3D economy process relies on reducing decision making cycles and their persistent capabilities (e.g. with rehearsal/simulation functionalities) to provide a safer workplace and collaborative environment. This may be understood through the 'bridge model' which not only integrates but surpasses the value chain model and the associated silos. This bridge model lets value creation rise out in new distributed dimensions coming from innovative practices, achievements and tangible outcomes.

Business cases were made, from those virtual worlds defined by Limayen, Hendaoui, and Thompson (2008). They aim at defining the technical, organizational and functional systems

\footnotetext{
*Corresponding author. Email: dbretones@escem.fr
} 
used. The goal of this paper is to understand how companies can use those 3D applications and VSN to create value. Those virtual worlds and VSN are first classified and defined. A double stage approach is then introduced to help companies find out what virtualization is. The first stage deals with the strategic position aimed at. The second one deals with the selection of the strategic operations which can be 'virtualized' through the activity theory framework and the transition from reality to 'virtual reality' enhanced with the bridge model. This approach has been tested over a 3-year period and 56 case studies coming from the international Intraverse awards. The Intraverse awards competition was created in 2007 (Quinio \& Réveillon, 2008). It gathers, through an international competition process, the world best usage of $3 \mathrm{D}$ virtual worlds within organizations as presented in the Intraverse awards (2010). Four issues of the Intraverse awards were held from 2007 to 2010. The 2009 Intraverse London ceremony awards can be viewed on a multimedia support (Réveillon, 2009). A practical study coming from the selected cases in 2009, the case of Michelin, is presented in the last section of this paper.

\section{Virtual social networks and organizations}

\section{State of the art}

The technical dimension of those VW originates in the industrial applications. According to Fuchs, Arnaldi, and Moreau (2006), the virtual reality allows users, via their avatar, to change the time, the place(s) and interact with a new world and others' avatars. First applications of virtual reality came from the technical field (Arnaldi \& Gerbault, 2009). Interactions between world users, as changes are carried out, make the virtual world constantly on the move, and this evolution seems to be improvised (Ortiz de Gortari, 2007).

There exists today more than $300 \mathrm{VW}$ listed in the world with an estimated 700 million web users and more than 150 million users with mobile phones. The most important ones are located in Asia ( $Q Q$ with 1 billion multi-media registered accounts) and Cyworld in the USA (Penguin Club and Neopets). Some of those VW are clearly dedicated to a young public (teenagers) or opened to a wide public (Second Life and Facebook with 500 million registered users using extensively 3D applications such as Scene Caster or the online game Farmville with 80 million registered accounts) and their in world and real world (RW) communities. These worlds allow new experiments where users can be free from time, space and gravity constraints. Social relations are regulated by the in world or the social network behavioural practice code and habit called community management.

Those 3D immersive VW allow the final user to get involved in the upstream design process. So they make easier the products and services customization by the companies. The user may form new virtual objects (content) but also change the world environment (context) and develop new communities and new linkages within VW. Companies try to capture the users' generated content and context through those 3D platforms, and must identify, listen and adapt their offers to what these communities say about them within these VW. A consumer is not viewed as an isolated individual but as an influential force in an online community. A clothes manufacturer may observe avatars trying its range of products in the virtual world, study the collections which are the most successful and propose customizations for marketing in tangible shops. Virtual worlds are closed, and for this reason each company selects an environment which may disappear. A possible solution could be found in the outcome of the 3D Metaverse worlds (METAVERSE Roadmaps, 2010) that is to say a set of virtual worlds communicating between themselves; another solution is the development of virtual world standards (Sivan, 2009). VW are increasingly perceived as an opportunity for business activity and some typologies of VW have already been proposed to promote studies and 
applications (Kim, Lyons, \& Cunningham, 2008; Messinger, Stroulia, \& Lyons, 2008). But these typologies generally do not include technology within social or business contexts.

\section{Definition and classification of $V W$}

In order to define and classify VW, a study was made on 60 international VW (Quinio \& Réveillon, 2008). This study was made through direct observations among the following VW (QQ, Second Life, Entropia and Facebook) enhancing online communities management such as what is happening through the usage of VSN, MMORPG and serious games. This study is different from the 56 case studies obtained from the Intraverse awards competitions from 2007 to 2010.

A VW is defined as a 3D and persistent environment linking up a human community through avatars. Each avatar may interact directly and freely with the other ones within the virtual social networks generated as it can make it on the virtual environment (objects and or contexts creation and changes).

In this survey of $60 \mathrm{VW}$, the following characteristics were used:

- communication analysis (dialog tool via chat, voice through IP);

- pictures analysis and graphics tool because the quality of a virtual world is partly assessed through the immersion process;

- consumer analysis (understand how the VW is used and by whom);

- VW analysis (dealing with the world and categories of actions related to the virtual environment).

The results distinguished three main VW categories:

(1) the scenario worlds: this category relies on a basic scenario from which all the actions carried out in this world have to be modelled such as serious games and MMORPG;

(2) the worlds relying on chats: the main goal of a visit is to allow the Internet users having subscribed to chat and interact within virtual communities;

(3) the worlds with parallel reality: this category is quite close to the present web. Users may go shopping, meet and wander around in the scenery without having goals to reach.

From those virtual environments Second Life was selected as it best illustrated the transition from the value chain concept to what we call the 'outlying clustered value creations'. Despite the fact that Linden labs, the founder of Second Life, implemented a major downsizing in the organization in June 2010, this VW seems to offer great opportunities for companies.

\section{Firms can create value}

The study of value creation in VW was made using case studies in a scientific approach (Yin, 1989). A survey was conducted on 56 companies from 2008 to 2010. The associated business cases were coming from the Intraverse award competitions (Intraverse awards, 2010). These cases were assessed by the Intraverse assessment committee. This committee is made up of academic experts and professionals. It ranks the proposed cases according to a list of criteria as shown in Table 1.

The cases received for the Intraverse awards competition may belong to seven categories: small and medium companies; big business; territorial communities; R\&D; education; project; serious games. 
Table 1. Intraverse case studies assessment matrix.

\begin{tabular}{ll}
\hline Marks by group of criteria & Case studies selection criteria \\
\hline $\mathbf{3 0}$ & Topic of the 3D virtual world/serious game \\
& Level of innovation \\
& Concerned audience and relative importance \\
& Strategic importance of the project (not yet online versus operating) \\
& International scope \\
& Stakeholders engagement \\
& Attitude $\mathbf{2 . 0}$ \\
& Number of exchanges done over the 3D platform \\
& Importance of the contributions as value creation \\
& Hierarchy levels concerned within the organization \\
& Quality of the intangible asset (island, building, 3D object) \\
& Clear graphics, ergonomics \\
$\mathbf{1 5}$ & Interaction \\
& Multimedia \\
& Update \\
& Feedback of the platform content \\
& Audience measures (traditional media, Internet, blog, wiki) \\
$\mathbf{1 0 0}$ & ROI (level of allocated resources versus measured return) \\
$\mathbf{5 0}$ & Strategic alignment of the organization versus 3D \\
& General quality of the application file \\
& Media impact obtained further to awarding it \\
&
\end{tabular}

\section{First stage: strategic positioning}

The results of the Intraverse awards from 2008 to 2010 are presented in Intraverse awards (2009) and Le blog des managers 2.0 (2008); and completed by a literature survey (Chang et al., 2008; Chen, Slau, \& Nah, 2008; Ives \& Junglas, 2008; Lee, 2008) which allowed studying the first experiments. All the categories of organizations have been scrutinized, from small to large companies, associations and administrations. The business models may be internal to a VW (for instance a real estate agency selling virtual islands to virtual residents in Second Life) or located at the real world border (a real estate agency selling real properties having had them first visited in a virtual way). The experiments described are relying on Porter's (1985) value chain (see Figure 1).

The targets of using those strategic tools may be internal (company employees) or external (customers and partners) within communities being on or off line. In Figure 1, the character's

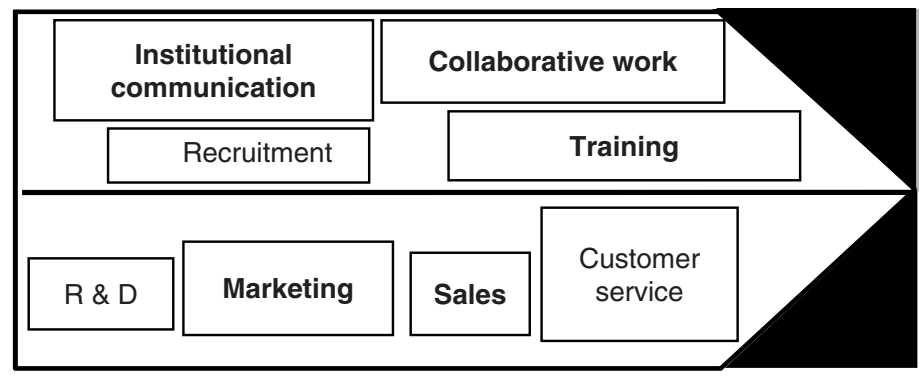

Figure 1. Organizations' experiments characteristics. 
size specifies the importance in volume of the experiments in the portfolio of 56 case studies. A few lessons can be drawn from the virtualization introduction inside the companies' activities. The initial investment to provide a presence, even imperfect, is limited and it allows the acquisition of a real knowledge of those new environments within which the immersion and the persistency are implemented in new managerial dimensions. Design risks may be limited having recourse to the 3D simulation. 3D immersive tools bring in a real added value for specific activities, such as training and marketing for instance. The crucial point for the companies is to select the adequate business activities and have the good ideas necessary to obtain productivity gains, stress reductions or build a competitive advantage. Two tracks may be outlined. The first one shows an external direction towards the institutional communication and then a marketing orientation to product co-creation and sales. The second one is internally oriented towards innovation, training and collaborative work. In this case, the goal is to save and protect resources and to increase the creativity. Some authors have proposed a classification of strategic attitudes for organizations that have a virtual and a real business (Goel \& Prokopec, 2009). Companies may have a specific virtual strategy, a virtual strategy parallel with a real one, a mirroring strategy and finally a virtual strategy linked with a real one.

To go beyond the classical value chain, showing the silos characterizing organizations, the expression 'outlying clusters value creations' (OCVC) was created. In a VW actors may cooperate and co-produce in multidimensional ways and generate OCVC. In Figure 1, the black area at the chain's tip shows the value creation area. The latter originates from the outlying clustered value creations obtained by the decompartmentalization of the organizations' traditional silos. The 'outlying clusters value creations' concept was first designed and tested from the Intraverse awards cases studied. The mechanism shows a spectrum from low potential to high potential value creation. In Figure 2, the graphic corresponds to a world leading continental European bank. The positioning of two businesses is presented. The company strategy may explain a positioning on one or the other limit of the spectrum; fostering value creation for stakeholders being inside and/or outside virtual communities. The initial presence of this bank in Second Life with its virtual building and the first avatars of the participating team members can be analysed as a mirror effect of the real world. Media coverage benefits can be related to a communication strategy and to an increased awareness for the brand on specific targets. The bank archipelago (including a selection of business units) in Second Life was developed later with a few virtual buildings and a strong customization of the participants' avatars. In this model, we distinguished a 'low added value creation area' bridge defined by the duplication of the real world activities and or the brand communication channels like in the tangible economy (Figure 2).

We also can notice a 'high added value creation area' bridge where the OCVC translate the synergies coming from the overall system. It formalizes the bridges between the RW and the VW in the framework of strategically managed activities (Quinio \& Réveillon, 2008). In addition to that, if the VW developments last as expected, the company will find in the VW, new collaborative work spaces and milestones.

This first stage of the approach allows the definition of a global positioning of the organization, and then leveraged activities, which can be virtualized and transcended, may be chosen.

\section{Analysing activities: the activity theory}

The activity theory analyses the human practices in a social context and in relation with tools (Leontiev, 1981; Vygotsky, 1978). It focuses on work and learning and defining activity as an essential component (Marciniak, 2009). An activity is a relationship between 


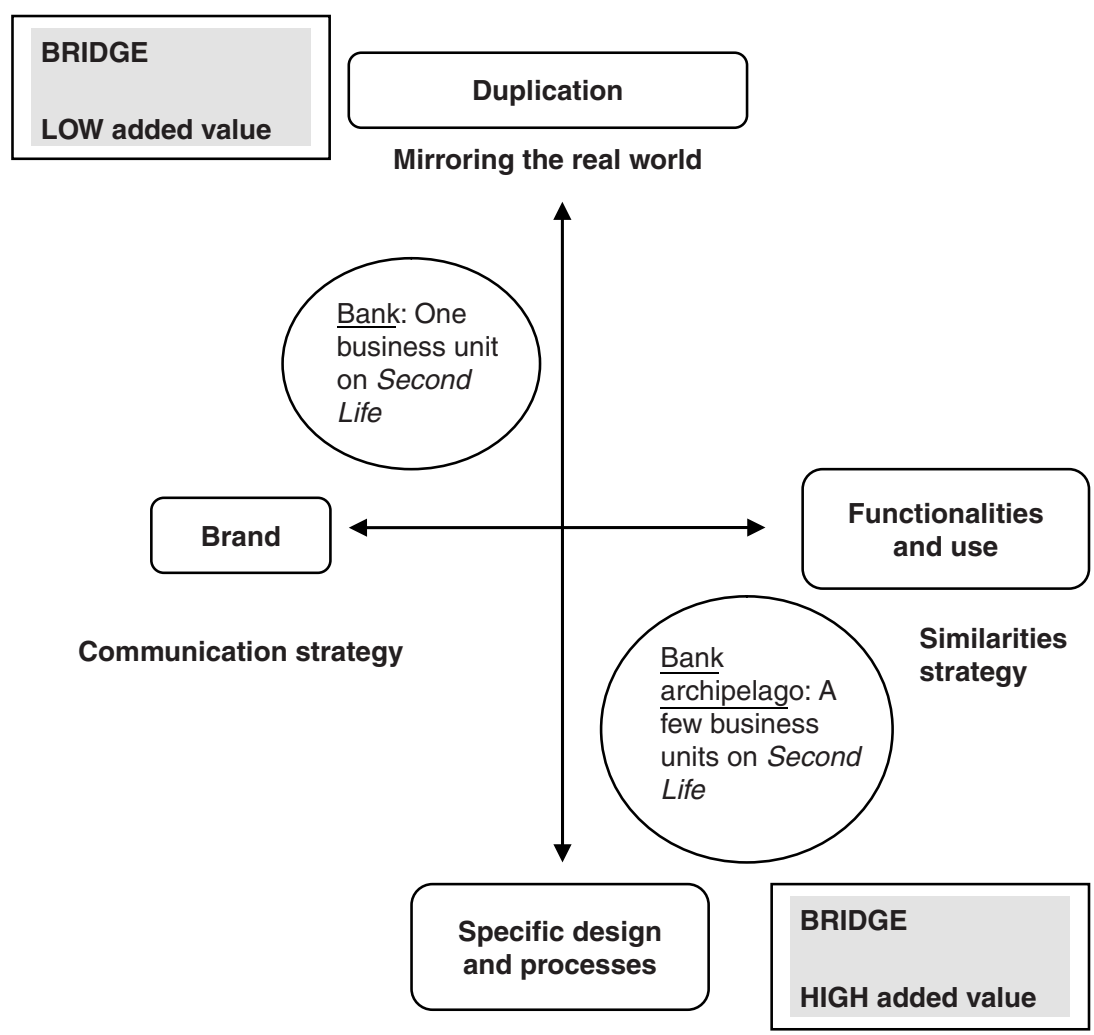

New discoveries and specific experiments

Figure 2. Bridge impact on value creation.

a subject (individual or group) and its environment through an object. This theory has been used in the studies on collective work (Hasan, 2003; Lorino, 2006). Observing activities allow understanding of the tools evolution and how they influence knowledge and social groups practices. Once the knowledge is assimilated, it is integrated in the tool to enrich it. In the most recent developments (Quinio, Marciniak, \& Réveillon, 2009), the triad subject/tool/object is studied within the organization context in VW (Figure 3).

The relationship between the subject and the goal is used not only by the tools but also the community which defines the rules, the organization and the context in which the subject or the subjects act. The global model (Figure 4) allows the representation of

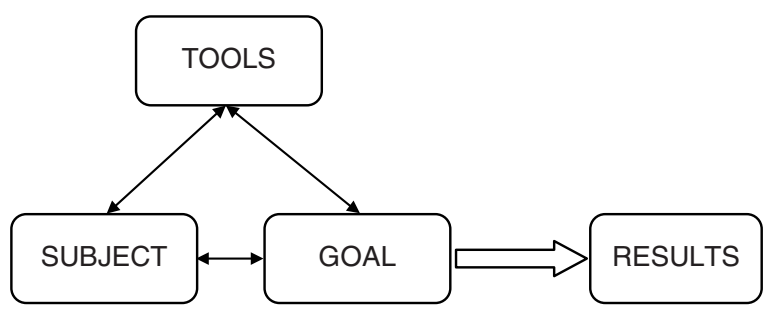

Figure 3. The activity theory triad. 


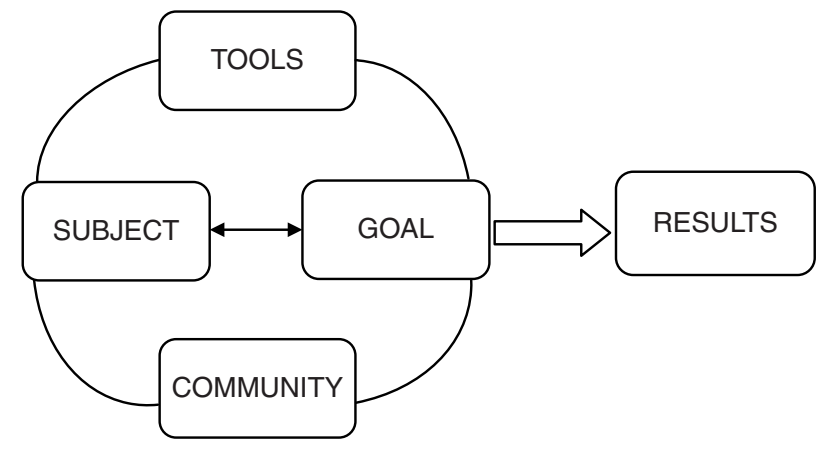

Figure 4. The activity theory global model.

activity systems or activities networks. For instance, the tool component of an activity may result from another design and achievement activity from a technical team. In addition, an activity may evolve towards a more complex activity. In the case of a system of activities, a main activity is determined, upon which are connected support or related activities.

The activity (level 1) is related to the goal. It is achieved through a run of actions (level 2) which define a part of the 'how to do it'. Actions are composed of operations (level 3) which define the 'how to do it' in specific conditions. The following example is proposed from the literature (Hasan, 2003). A designer wants to lay out a product (activity) to be marketed (goal). Among the activities to achieve, he has to manufacture the product (action) which will make use of data acquisition, implemented with specific engineering tools (operations) (Figure 5).

The goal is to compare the activity taking place in the real world and the one going off in a virtual world (in world). Every time that the VW possibilities allow for a real action to be turned into a virtual operation embedded in the tool, participants may face more complex actions. With this point of view on activity in a VW, it is possible to identify which activity can create value for the organization. In Figure 5, the descending direction corresponds to a simplification of the studied practice. The increase in the number of operations and the decrease in the number of actions allow to automate a part of the work and to free some time to tackle more complex activities. The knowledge really acquired is grafted therefore in the tool during operations. Then, the knowledge is made re-usable in another action or in another activity. Relying on developments obtained from the activity theory, one may assume that the components transferred from the VW to the RW constitute the knowledge embedded in the tool (including the avatar itself) through the virtualized activities. Thus company borders are changed as the VW and the RW fit in.

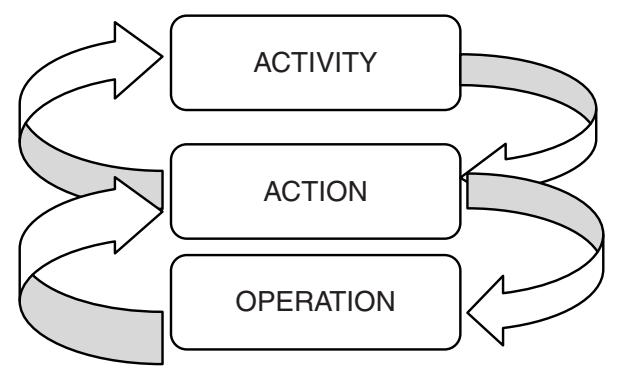

Figure 5. The three activity levels. 


\section{Studying the transition points: the bridge model}

The VW practice for a company requires necessarily shifting at a certain time from the real world to the VW. It requires going over activities in the VW then to return in the RW. The process analysis (Hammer \& Champy, 1993) allows specifying when and where the transition to the virtual world may happen and when and where the return to the real world takes place. In our approach, virtualization is not opposed to reality but understood as a space opening new opportunities (Quinio et al., 2009). Virtualization is an unrivalled environment to experience milestone achievements (including experiential marketing for brands). The key questions are dealing with the transition points between the VW and the RW. This can be shown peculiarly in the consumption of virtual goods which can never be totally substituted to the consumption of tangible goods such as described by Siddiqui and Turley (2006). Knowledge management and value creation are placed at the interface between the RW and the VW. Some activities happening in the RW may not be held in the VW and some activities can be achieved only inside the immersive 3D environment. On the other hand, a significant number of activities are improved with this cross fertilization system dealing with the following stages: design integration; achievement; and discrepancies reduction in both worlds.

\section{Business case: a training centre for the enterprise architecture}

This case study introduced by Michelin comes from the London Intraverse awards competition in 2009 (Intraverse awards, 2009). In the course of 2007 this European industrial tyre and rubber group was facing strong rivalry from its world competitors in Asia and in North America. This company is one of the leading players in the global tyres and rubber world market value approaching US\$115 billion in 2009 (Table 2).

More than $94 \%$ of this market is distributed on three continents: Asia; Europe; and North America (Table 3). Among decisions made to foster the firm's global services development, the Board of Directors wished to improve the firm's productivity and an enhanced creative team work approach on a worldwide basis. This orientation supported the goals to grow the base of global customers and to accelerate the products and services delivery cycles. In this context, the firm wanted to develop Enterprise Architecture projects and to improve the effectiveness of training on this complex topic. For the understanding of this case, we also rely on a case study of Forrester (Driver, 2008).

\section{All traditional teaching slides based approaches were not satisfactory}

The chief information officer and the enterprise architecture (EA) IT teams were assigned a major role in promoting the new global teaching environment relying on an innovative collaborative and immersive solution (Le blog des managers 2.0). All traditional slide based

Table 2. Global tyres and rubber market value: 2005-2009.

\begin{tabular}{lc}
\hline Years 2005-2009 & Market value: US\$ billion \\
\hline 2005 & 110 \\
2006 & 118 \\
2007 & 130 \\
2008 & 120 \\
2009 & 115 \\
\hline
\end{tabular}

Source: Datamonitor, March 2010. 
Table 3. Global tyres and rubber market segmentation.

\begin{tabular}{lc}
\hline Territory & \% share, by value, 2009 \\
\hline Asia Pacific & 34.4 \\
Europe & 26.5 \\
North America & 33.6 \\
Rest of the World & 5.5 \\
\hline
\end{tabular}

Source: Datamonitor, March 2010.

approaches were unsatisfactory as they appeared to be too conceptual and too complex. The challenge was to train, in a first period, 163 IT people in North America, Europe and Asia to understand the EA, so that they would design and deliver global applications based on EA.

A virtual and totally interactive training centre was established with the support of an IT agency in March 2008. The EA group within the IT division launched a private two island region in Second Life designed to train the IT professionals on architecture concepts. The total training package was redesigned and simplified. It was then made virtual to be accessible from anywhere, without requiring a change of location. This virtual environment allowed teaching complex concepts in new ways. Trainees used interactive teaching materials built into the environment which helped them work on business concepts, process management, functional blocks and business services relying on service oriented architecture. The importance of the IT governance was stressed by placing a space dedicated to teaching and learning about governance at the geographical centre of the region. The training sessions were under the supervision of a coach trainer, but they were also designed for self-training.

To introduce some fun, the participants, who completed the exercises, are allowed to race against their peers in virtual go-karts around a track, where the centrepiece was a giant company logo. This conveys within the company an image of EA as something new and exciting (Driver, 2008).

\section{Costs assessment}

A virtual world development agency was hired to build the Second Life region. It took about two months and the cost was close to $€ 60,000$, which is more or less the same as what was spent for the traditional classroom training. In this first stage the traditional classroom cost is increased by the Second Life training cost. However reducing the training cost was not the firm's main objective. In the future, training within the virtual environment could replace part of the traditional training methods (Driver, 2008). Thus the global training cost per employee might be reduced. Nevertheless, specific training actions which require face to face situations will not disappear, despite the virtual training environment take off. During this experiment, significant time and budget savings were made on transport and meeting place costs.

\section{The pedagogical approach}

Training was based on a mix of PowerPoint presentations and interactive lessons where trainees manipulated objects. Training the IT professionals on the basic navigation skills, how to move an avatar in their new Second Life environment, takes only few minutes. Trainees attend sessions using their avatars, sit in an audience with the avatars of their peers and listen to a presentation. Trainees visit a variety of interactive sessions where they can learn to build a road map. IT projects are represented by circles with related costs. The trainees may click on them and then match the cost of the project with the company's goals and business priorities. 
A good or bad answer turns the clicked circle green or red. Trainees are taught to build business processes which fit with the company's strategic options. They can also learn how to turn the business processes into business services delivered across activities as shown by Driver (2008).

Simulation is a complementary part of this training. It involves employees in virtual situations where they can gain experience which will benefit the company later. The trainees were asked to express their satisfaction level on the EA methodology implemented and on their Second Life immersive environment perception. The 163 trainees answered a basic questionnaire, the results are shown in Table 4.

These results are considered as promising by the EA group. The EA management believe virtual worlds are a great way to present, to train and to interact. It allows the unleashing of group members' creativity but it also requires a careful preparation prior to being implemented.

\section{Additional benefits}

Training the IT professionals to use the Second Life virtual environment was the first stage in an ambitious programme within the Michelin group. The positive results obtained by the IT professionals triggered off the scheduling of more training sessions within the group.

The firm aims at training more than 2000 executives in both the conceptual and functional aspects of EA. Islands were used for internal events such as communication of the 2009 objectives. They are now used to set up meetings and conferences. The firm is investigating other opportunities to use the virtual worlds for training in other areas.

\section{Confrontation with our model}

The firm's strategic position was obviously in the 'high value area' of Figure 2. The VW platform did not propose only the duplication of a traditional learning platform but additional functionalities. The $3 \mathrm{D}$ environment allowed shifting a traditional teaching environment to a new learning concept. By using the capacity of the VW (3D and immersion) the participants were able to integrate their new knowledge in the tool. The trainees were not only reading, but were also manipulating, complex concepts via their avatar. The outcome of the satisfaction survey in Table 4 shows that participants have transferred their knowledge from the VW to the RW.

\section{Conclusion}

In this paper, the theoretical input relies mostly on the activity theory and on the concept of outlying cluster value creations observed and measured from our 56 case studies carried out over a 3-year period. The cases studied dealt with the positioning of one, or a few,

Table 4. EA methodology understanding and immersive environment satisfaction.

\begin{tabular}{lcc}
\hline & $\begin{array}{c}\text { I understand the EA } \\
\text { methodology }(\%)\end{array}$ & $\begin{array}{c}\text { Second Life appropriate to learn } \\
\text { about EA }(\%)\end{array}$ \\
\hline Very true & 61 & 59 \\
True & 35 & 38 \\
Somewhat true & 4 & 3 \\
Not true & 0 & 0 \\
\hline
\end{tabular}

Source: Intraverse awards (2009). 
strategic selections of business units and activities in the virtual world. Once the activities are selected, the way in which an optimal value can be co-produced in one or a few selections of communities, has to be thought through the framework of an open innovation process. As we saw, companies may have a specific virtual strategy, a virtual strategy parallel with a real one, a mirroring strategy and/or a virtual strategy linked with a real one (Goel \& Prokopec, 2009).

\section{Training implications}

Integrating the $3 \mathrm{D}$ environments in the teaching and training solutions is possible. It brings new and innovative aspects in the field of training. Trainees may learn quickly to manipulate objects and concepts. They are able to redesign processes and business roadmaps. They can also assess the services delivery quality and relevance within their organizations. These 3D immersive solutions may be mixed with traditional training formulas. From the Intraverse experiences, it can be suggested that academic institutions and organizations could take advantage to enhance the role of 3D environments in their teaching and training activities. Promoting the 3D training might become a differentiation criterion between organizations in the future.

\section{Managerial implications}

From a managerial perspective, integrating the 3D immersive environment in a strategic approach requires a few pre-requisites. Management has to be aware of the potential value creations that can be repatriated from the VW to the RW. Manager awareness is one thing, but a potential value creation has to be turned into a project showing the many possibilities proposed by the $3 \mathrm{D}$ environments. With the EA project, it has been shown that the new functionalities integrated in the tools allowed for the manipulation of objects in a new and creative way. Experiences acquired and integrated in the tools allow firms to identify the outlying clustered value creations which will position the company strategy in the "high value area' of Figure 2. The integration of the OCVC opportunities in a company strategy requires an adequate testing, prior to the strategy implementation. Once new OCVC have been identified and tested, it is necessary to assess their potential in terms of additional revenues for the company. In addition to that, the transfer to the RW from concepts tested in the VW may affect significantly the company organization and its managerial practices. The strategic integration of the OCVC potential requires managers to show a forerunner profile as well as business developers' skills, supported with a strong taste for assessing innovative outcomes.

What is at stake for a company is to be able to differentiate from its competitors and to reinforce its strategic position. This can be done through something like the EA project depicted above which can be prepared and structured before being tested in a programme. It is also possible to imagine that a small innovation entity, related to the corporate management, might test the 3D environments and their subsequent new positioning for related potentialities. Recommendations could then be made to the management, whose responsibility would be to choose to commit investment in those 3D immersive ventures, or not.

Taking into account the major developments of the 3D environments, it seems difficult for companies to do without them. The 3D environments could be used to support the creation of blue ocean market segments as introduced by Kim and Mauborgne (2005). One of the possible uses of these $3 \mathrm{D}$ environments would be to make easier the achievement of new strategic options. It seems difficult for managers not to get involved in what turns out to be a possible source of value creation. Business schools should also be tasked with integrating these 
immersive tools into their educational programmes for both current and future managers, not only to stimulate their intellectual contribution in the development of strategy, but to open up their eyes to strategic capabilities.

\section{$3 D$ environments technical limits}

This research has to be reinforced with new cases, showing details of technological environments. On a technical point, solutions such as the Second Life environment are proprietary ones. There is a strong demand from companies which want to implement these solutions to move to non-proprietary '3D' standards. Companies may invest in proprietary solutions, only if they are maintained on the medium/long term. They want to secure their 3D investment. A real 3D market development seems to be dependent on the outcome of nonproprietary standards shared by a large group of the software developer community.

\section{Limitations and future research orientations}

The $3 \mathrm{D}$ cases, studied within the Intraverse awards competitions, are limited to a small number. A more extended period of survey would allow a better understanding of the way the VW work and their relationships with the RW. This research has to be reinforced with new cases showing details on the technological environments. Scientific analysis, applied to the new 3D solutions, will play a major role in the coming years. The R\&D investigators in this field will have to test and assess the innovative solutions proposed and their related benefits. Their analysis will orientate the possible growth of the 3D immersive markets in the coming years. The main direction of the research is to study in depth the cases identified in the Intraverse competitions. It is also planned to develop a serious game as a complementary field of expertise. Ultimately, this study describes the new capabilities proposed to the management in terms of knowledge urbanization with $3 \mathrm{D}$, within strategically evolving organizations.

\section{References}

Arnaldi, B., \& Gerbault, S. (2009). Humains virtuels et collaboration dans un environnement virtuel de formation. Techniques et sciences informatiques, 28, 741-766.

Chang, K.T.T., Koh, A.T.T., Low, B.Y.Y., Santos Onghanseng, D.J., Tanoto, K., \& Thuong-Thuong, T.S. (2008). Why I love this on line game: The MMORPG stickiness factor. International Conference on Information Systems (ICIS) 2008 proceedings. Paper 88. Retrieved from http:// aisel.aisnet.org/icis2008/88

Chen, X.F., Slau, K., \& Nah, F.F.H. (2008). Adoption of 3-D virtual worlds for education. International Conference on Information Systems (ICIS) 2008 proceedings. Paper 113. Retrieved from http://aisel.aisnet.org/icis2008/113

Driver, E. (2008). Michelin uses Second Life for enterprise architecture training. Retrieved from http:// www.forrester.com/rb/Research/case_study_michelin_uses_second_life_for/q/id/46085/t/2

Fuchs, O., Arnaldi, B., \& Moreau, G. (2006). Le traité de la réalité virtuelle, volume 4: Les applications de la réalité virtuelle. Paris: Les Presses - Mines Paris (Science, Mathématiques \& Informatique).

Goel, L., \& Prokopec, S. (2009). If you build it will they come? An empirical investigation of consumer perceptions and strategy in virtual worlds. Electron Commerce Research, 9, 115-134.

Hammer, M., \& Champy, J. (1993). Le reengineering: Réinventer l'entreprise pour une amélioration spectaculaire de ses performances. Paris: Editions Dunod.

Hasan, H. (2003, January 6-9). An activity-based model of collective knowledge. Proceedings of the 36th Hawaii International Conference on System Sciences, Big Island, HI.

Intraverse awards. (2009, May 9). Re: Intraverse 2009-Liste des lauréats. Retrieved from http:// www.intraverse.eu/news/intraverse-awards-2009-laureats

Intraverse awards. (2010, January 10). Re: International Intraverse awards 2010. Retrieved from http://www.intraverse.eu/ 
Ives, B., \& Junglas, I. (2008). APC forum: Business implications of virtual world and serious game. MIS Quarterly Executive, 7(3), 151-155.

Kim, H.M., Lyons, K., \& Cunningham, M.A. (2008). Towards a theoretically-grounded framework for evaluating immersive business models and applications: Analysis of ventures in Second Life. Journal of Virtual Worlds Research: Past, Present and Future, 1(1), 1-19.

Kim, W.C., \& Mauborgne, R. (2005). The blue ocean strategy: How to create uncontested market space and make the competition irrelevant. Boston, MA: Harvard Business School Press.

Le blog des managers 2.0. (2008, June 5). Re: Résultats du prix Intraverse. Retrieved from http:// b-r-ent.com/news/resultats-du-prix-intraverse-2008

Le blog des managers 2.0. (2009, July 6). Re: La vidéo du Chief Architecture Officer de Michelin [Video file]. Retrieved from http://b-r-ent.com/news/world-intraverse-awards-london-7-mai-09live-second-life-et-trophees-loov\#comment_14

Lee, P.D. (2008, March 29). Do supply chains exist in virtual worlds? Paper presented at the 2008 Northeast Decision Sciences Institute Conference, School of Business, Rutgers, Camden, Brooklyn, USA.

Leontiev, A.N. (1981). Problems of the development of mind. Moscow: Progress.

Limayen, M., Hendaoui, A., \& Thompson, C.W. (2008). 3D social virtual worlds research issues and challenges. IEEE International Computing, 12(1), 88-92.

Lorino, P. (2006, September). La notion de processus en gestion comme première approche des activités coopératives complexes. Paper presented at the Cerisy Conference on Des pratiques coopératives: Constitution des agents, constitution des œuvres, Cerisy, France.

Marciniak, R. (2009). Coordination, théorie de l'activité et théories des organisations. Paris: Editions Presses Universitaires Paris Ouest Nanterre La Défense.

Messinger, P., Stroulia, E., \& Lyons, K. (2008). A typology of virtual worlds, historical overview and future directions. Virtual Worlds Research, 1(1), 1-18.

METAVERSE Roadmaps. (2010). Pathways to the $3 D$ web. Retrieved from http://www. metaverseroadmap.org/

Ortiz de Gortari, A. (2007, September). Second Life survey: User profile for psychological engagement \& gambling. Paper presented at the Virtual 2007 Conference, Stockholm, Sweden.

Porter, M. (1985). Competitive advantage. New York: Free Press.

Quinio, B., Marciniak, R., \& Réveillon, G. (2009, June 10-12). La recherche sur les univers virtuels une proposition de démarche fondée sur l'activité. Paper presented at the meeting of AIM, Marrakech, Morocco.

Quinio, B., \& Réveillon, G. (2008). Economie 3D et intégration des univers virtuels. Vie \& Sciences Economiques, 179-180, 76-93.

Réveillon, G. (2009, May 18). 2009-Wiva-Intraverse-awards-Apply-London-New3S [Video file]. Retrieved from http://www.youtube.com/watch?v=5MK-10dCMzs

Siddiqui, S., \& Turley, D. (2006). Extending the self in a virtual world. Advances in Consumer Research, 33, 647-648.

Sivan, Y. (2009). Overview: State of virtual worlds standards in 2009. Journal of Virtual Worlds Research, 2(3), 3-18.

Vygotsky, L.S. (1978). Mind and society. Cambridge, MA: Harvard University Press.

Yin, R.K. (1989). Case study research: Design and methods (2nd ed.). Newbury Park, CA: Sage. 